\title{
O contexto de exercício clínico do médico de família tem determinantes que influenciam a prestação de cuidados de saúde
}

Rui Nogueira, ${ }^{1}$ Tiago Maricoto ${ }^{2-3}$

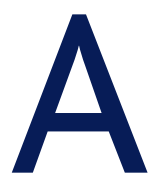
Definição Europeia da WONCA ${ }^{1}$ faz referência a três áreas de intervenção fundamentais do médico de família: a técnico-científica, a comunicação e a gestão clínica. Estas áreas de intervenção são muito bem conhecidas dos médicos de família e compreensíveis no nosso quotidiano.

A qualidade da prática clínica e os ganhos em saúde possíveis dependem em grande parte do número de utentes que o médico de família tem a seu cargo e do contexto onde exerce. Para assegurar o rigor do ato médico e a evolução dos cuidados de saúde primários é importante valorizar o contexto sociodemográfico de exercício do médico de família e atuar sobre esta realidade. Eu sou eu e a minha circunstância e se não a salvo, não me salvo a mim mesmo (Ortega e Gasset).

Além da defesa dos interesses do doente importa defender o médico e respeitar os mais elementares princípios humanistas e a preservação da saúde de ambos. A integração do contexto de exercício no cálculo da dimensão padrão das listas de utentes contribuirá para garantir maior equidade e coesão nacional, além de melhores resultados e maior segurança.

A consolidação de unidades de saúde de proximidade com equipas multiprofissionais é um contributo para o desenvolvimento e o enquadramento necessário para a valorização profissional dos médicos de família e para a sustentabilidade do Serviço Nacional de Saúde, em defesa do utente. Mas não tem sido fácil criar novas unidades de saúde, apesar de termos profissionais disponíveis, assim como utentes com necessidades de cuidados de saúde em várias localidades. O mundo é fundamentalmente não-linear. ${ }^{2}$ A Teoria da Complexidade (Quadro I) pode ajudar-nos a entender me-

1. USF Norton de Matos, ACeS Baixo Mondego

2. USF Aveiro-Aradas, ACeS do Baixo Vouga

3. Faculdade de Ciências da Saúde, Universidade da Beira Interior lhor algumas realidades dos nossos dias e o caos permite desenvolver o comportamento criativo ${ }^{2}$ necessário ao novo ciclo dos cuidados de saúde primários em Portugal.

A desordem obriga a criar novas formas de ordem, ${ }^{2}$ mas é necessário fazer evoluir os conceitos com conhecimento da realidade das unidades de saúde em todo o país. Ora, quando estamos à beira de conseguir a cobertura universal, num cenário de disponibilidade de médico de família para todos os residentes em Portugal, temos várias unidades de saúde com $20 \%$ ou $30 \%$ dos utentes inscritos sem médico de família atribuído. Mais do que dar médico de família a todos os portugueses (Programa de Governo) é importante criar condições dignas para o exercício clínico e para a defesa inequívoca da saúde dos utentes e dos médicos.

Esperemos que as medidas de apoio ao interior - agora na estratégia do Governo - passem pela criação de condições ao desenvolvimento de unidades de saúde de proximidade, tendo em conta os contextos sociodemográficos e não apenas a idade dos utentes.

A abordagem sistémica permite saber que as organizações são "subsistemas integrados no macrossistema ambiental que as envolve". ${ }^{2}$ As diferentes realidades sociodemográficas, geográficas e culturais, o estado de saúde da comunidade e os recursos técnicos e humanos disponíveis são diferentes determinantes que influenciam a saúde da pessoa e a recuperação da doença. A acessibilidade, a continuidade, a complementaridade e a personalização de cuidados de saúde impõem a implementação de unidades de saúde de proximidade que garantam equidade e cuidados efetivos, devidamente dotadas dos meios adequados às necessidades de saúde da comunidade.

Está bem demonstrado que listas de utentes sobredimensionadas são desadequadas para a qualidade da prática médica, estando associadas, por exemplo, a consultas mais curtas, menos visitas domiciliárias, maiores taxas de referenciação hospitalar, piores coberturas oncológicas e pior 
QUADRO I. A Teoria da Complexidade e as organizações

"O desenvolvimento da teoria do caos nos anos 70 e 80 sugeriu um modelo muito diferente para a maneira como as coisas ocorrem. O mais importante avanço das últimas décadas do século 20 foi a perceção de que o mundo é fundamentalmente não-linear.

Parte do que se tornou a ampla ciência da dinâmica não-linear, ou teoria da complexidade, ligando disciplinas tão diversas quanto física, biologia, química, economia e sociologia, o caos designa áreas de 'instabilidade de fronteira' como entidades que se movem entre o equilíbrio de um lado e a completa situação randômica de outro. Nesta área apenas o comportamento criativo ocorre."

desempenho nos cuidados de diabetes. ${ }^{3-7}$ Por outro lado, listas de utentes mais pequenas e adequadas estão associadas a consultas mais longas, a menos prescrições medicamentosas e a maior promoção de saúde e satisfação dos utentes. ${ }^{8}$

A dimensão das listas de utentes em Portugal tem vindo a aumentar progressivamente e está bem demonstrado que se aproxima do estado de saturação para fazer face a todas as atividades da agenda da MGF. ${ }^{9}$

A APMGF está a desenvolver um modelo de unidades ponderadas e ajustadas (UPA) por unidade de saúde. As diferenças existentes nos contextos de exercício clínico salientam as iniquidades que se foram criando e obrigam a pensar numa nova métrica das listas de utentes. A ponderação das listas de utentes é insuficiente se considerarmos apenas as idades dos utentes, mas será mais realista se contarmos com o contexto sociodemográfico de exercício da prática clínica, tendo em conta as diferenças regionais e o envelhecimento da população.

Na situação atual é notória a assimetria de UP por utente em função do tipo de unidade de saúde. As UCSP têm mais UP por utente em todas as regiões e principalmente no Alentejo, denotando a maior concentração de utentes idosos nestas unidades.

Por sua vez, o contexto social e os recursos da comunidade são fundamentais na prática clínica do médico de família, ${ }^{10-12}$ pelo que a localização geodemográfica da unidade de saúde, o seu estado de desenvolvimento, os constrangimentos de instalação, as limitações estruturais, a forma de constituição da equipa multiprofissional e a sua consolidação, as lideranças, a participação da comunidade e a sua literacia e a capacitação e estado de saúde da população são determinantes que devem ser considerados e incluídos na definição da métrica das listas de utentes.

Os “ambientes competitivos são aqueles que incentivam a criação de relações não-lineares no processo de gestão que favorece a diversidade, permitindo a geração de maior número de soluções criativas". ${ }^{2}$ No contexto atual é urgente evoluir na resolução de assimetrias geográficas e locais e garantir a proximidade do exercício profissional do médico de família no contexto de unidades de saúde alicerçadas em equipas multidisciplinares. Conhecendo as dimensões e dificuldades da prática clínica, o contexto de exercício profissional e o perfil de consumo de cuidados de saúde será possível e necessário redimensionar as listas de utentes.

Esta fase de evolução tem uma janela de oportunidade que não é possível perder. Assim, temos vindo a desenvolver um algoritmo de ponderação e ajustamento da dimensão das listas de utentes com base na carga de trabalho e nas características da unidade de saúde e do local de prestação de cuidados de saúde.

Este novo paradigma deverá permitir definir a dimensão das listas de utentes com base num valor padrão de Unidades Ponderadas e Ajustadas (UPA).

A necessidade de maior consumo de cuidados de saúde e a maior complexidade do contexto da unidade de saúde devem determinar listas de utentes padrão de menor dimensão em número de pessoas.

Esta nova métrica está desenhada para tentar colmatar, por um lado, a excessiva carga de trabalho que alguns contextos de exercício têm representado e, por outro lado, ajudar a ultrapassar a dificuldade em fixar novos colegas em localidades de elevada complexidade, como é o caso de unidades de saúde mais carenciadas e os contextos sociais mais adversos.

Com a nova métrica fica facilitada a formação de novas unidades de saúde de proximidade em qualquer região do país, fundamentadas em equipas multidisciplinares e baseadas em UPA.

Nos contextos de elevado consumo e maior complexidade, a lista de utentes padrão deverá ter menor dimensão. Importa garantir que a carga de trabalho seja equivalente e tenha em conta as diferenças de contexto de exercício. Por outro lado, é importante garantir as condições de acesso 
dos doentes e o rigor e a segurança do ato médico.

Alguns ajustamentos são óbvios e necessários:

\section{- Ajustamentos à carreira}

Médicos recém-especialistas em MGF, em início de carreira numa unidade de saúde, no primeiro ano de exercício, devem iniciar com uma redução da lista padrão, iniciando com $65 \%$ do valor padrão, o que corresponde a 1533 UPA.

\section{- Ajustamento à carga horária}

Médicos de família com horário reduzido, de acordo com as disposições previstas na lei geral do trabalho aplicável à função pública (como, por exemplo, profissionais com atividade académica ou com menores a cargo de idade inferior a 12 anos) deverão assumir listas de utentes padronizadas na relação de 59 UPA por cada hora de trabalho semanal.

Por outro lado, médicos de família que pretendam assumir dimensões de lista de utentes superiores ao padronizado deverão ser também remunerados de forma suplementar na mesma proporção, seguindo assim a regra de incremento de 59 UPA por cada hora semanal de trabalho adicional, de acordo com a lei.

\section{- Ajustamentos a outras atividades}

Outras atividades - académicas, formativas, científicas, de gestão, institucionais ou governativas ou outras - deverão ser consideradas para determinação da dimensão da lista de utentes dos médicos de família com estas atividades.

As iniquidades existentes no país são preocupantes e exigem medidas de correção. As unidades de saúde de proximidade devem ter condições equivalentes e adequadas ao contexto sociodemográfico dos seus utilizadores, tendo em conta os recursos disponíveis na comunidade.

As oportunidades devem ser aproveitadas e as aposentações de centenas de médicos de família nos próximos três anos criam condições para redimensionar as listas de utentes. É necessário dar um impulso na criação de unidades de saúde com equipas multiprofissionais motivadas em locais onde hoje não é possível com as exigências atuais.

A fundamentação das novas orientações deve ser robusta, realista e contribuir para a resolução do sobredimensionamento das listas de utentes. A transição deve ser progressiva e não criar ruturas. $\mathrm{O}$ investimento nos cuidados de saúde primários deve ser inequívoco. A valorização do SNS é um imperativo que defendemos e promovemos com o investimento sustentável nos cuidados de saúde primários.
Este trabalho de ajustamento da lista de utentes ao contexto de prática clínica apresenta-se, assim, como fundamental para uma prestação de cuidados de saúde com qualidade, prevenindo acontecimentos adversos e o erro médico e, acima de tudo, respeitando a pessoa e a dignidade do ato médico.

\section{REFERÊNCIAS BIBLIOGRÁFICAS}

1. WONCA Europa. A definição europeia de medicina geral e familiar (Clínica geral / Medicina familiar). WONCA Europa; 2002. Available from: http://www.woncaeurope.org/sites/default/files/documents/European\%20Definition\%20in\%20Portuguese.pdf

2. Ponchirolli O. Teoria da complexidade e as organizações [The theory of the complexity and the organizations]. Diálogo Educ Curitiba. 2007;7 (22):81-100. Portuguese

3. Campbell JL, Ramsay J, Green J. Practice size: impact on consultation length, workload, and patient assessment of care. Br J Gen Pract. 2001; 51(469):644-50.

4. Armstrong $D$, Britten $N$, Grace J. Measuring general practitioner referrals: patient, workload and list size effects. J R Coll Gen Pract. 1988;38 (316):494-7.

5. Dahrouge S, Hogg W, Younger J, Muggah E, Russell G, Glazier RH. Primary care physician panel size and quality of care: a population-based study in Ontario, Canada. Ann Fam Med. 2016;14(1):26-33.

6. Angstman KB, Horn JL, Bernard ME, Kresin MM, Klavetter EW, Maxson J, et al. Family medicine panel size with care teams: impact on quality. J Am Board Fam Med. 2016;29(4):444-51.

7. Fernandes JL. Impacto da dimensão da lista de utentes dos médicos de família na qualidade dos cuidados prestados [Dissertation]. Porto: Faculdade de Economia da Universidade do Porto; 2017.

8. Wilson A, Childs S. The relationship between consultation length, process and outcomes in general practice: a systematic review. $\mathrm{Br} J$ Gen Pract. 2002;52(485):1012-20.

9. Pinto $D$, Corte-Real $S$, Nunes JM. Actividades preventivas e indicadores: quanto tempo sobra? [Preventive activities and performance indicators: how much time is left?]. Rev Port Clin Geral. 2010;26(5):455-64. Portuguese

10. Wong E, Stewart M. Predicting the scope of practice of family physicians. Can Fam Physician. 2010;56(6):e219-25.

11. Barros PP, Lourenço A, Moura A, Correia F, Silvério F, Gomes JP, et al. Politicas públicas de saúde, 2011-2014: avaliação do impacto [Internet]. Lisboa: NOVA Healthcare Initiative - Universidade Nova de Lisboa; 2015. Available from: http://www.unl.pt/data/noticias/2015/estudo_impacto_saude/politicas_publicas_em_saude.pdf

12. Monterde $D$, Vela E, Clèries M. Los grupos de morbilidad ajustados: nuevo agrupador de morbilidad poblacional de utilidad en el ámbito de la atención primaria [Adjusted morbidity groups: a new multiple morbidity measurement of use in primary care]. Aten Primaria. 2016;48(10): 674-82. Spanish

\section{ENDEREÇO PARA CORRESPONDÊNCIA}

Rui Nogueira

rui.artur.nog@gmail.com 